\title{
Epigenetic roles of PIWI proteins and piRNAs in colorectal cancer
}

\author{
Fatemeh Sadoughi ${ }^{1}$, Seyyed Mehdi Mirhashemi ${ }^{2^{*}}$ (I) and Zatollah Asemi ${ }^{1^{*}}$
}

\begin{abstract}
Small non-coding RNAs (sncRNAs) are a subgroup of non-coding RNAs, with less than 200 nucleotides length and no potential for coding proteins. PiRNAs, a member of sncRNAs, were first discovered more than a decade ago and have attracted researcher's attention because of their gene regulatory function both in the nucleus and in the cytoplasm. Recent investigations have found that the abnormal expression of these sncRNAs is involved in many human diseases, including cancers. Colorectal cancer (CRC), as a common gastrointestinal malignancy, is one of the important causes of cancer-related deaths through the entire world and appears to be a consequence of mutation in the genome and epigenetic alterations. The aim of this review is to realize whether there is a relationship between CRC and piRNAs or not.
\end{abstract}

Keywords: PiRNA, PIWI protein, Epigenetic, Colorectal cancer

\section{Introduction}

Every function executed in our cells is conducted and monitored by a variety of genes which are altogether making up our genome. For years, it was believed that 98\% of DNA was "junk" because of the non-coding parts but today, lines of researches have proven that these parts of DNA have some biological functions, as well. In our knowledge, more than $70 \%$ of the human genome is actively transcribed but protein-coding genes make only $1-2 \%$ of the genome, and the major group of transcripts is noncoding RNAs (ncRNAs). Non-coding genes contain introns, pseudogenes, repeat sequences, and cis/ trans-regulatory elements and they can operate as RNAs without any translation [1, 2]. Recent investigations on RNAs have suggested that non-coding RNAs (ncRNAs) make $99 \%$ of the total RNA content in every cell

\footnotetext{
*Correspondence: mirhashemismm@gmail.com; Asemi_r@yahoo.com ${ }^{1}$ Research Center for Biochemistry and Nutrition in Metabolic Diseases, Institute for Basic Sciences, Kashan University of Medical Sciences, Kashan, I.R. of Iran

${ }^{2}$ Metabolic Diseases Research Center, Research Institute for Prevention of Non-Communicable Diseases, Qazvin University of Medical Sciences, Qazvin, Iran
}

[3]. Additionally, some researches showed that a part of ncRNAs are functional [4]. NcRNAs are categorized by their function into three groups: housekeeping ncRNAs (like ribosomal RNAs (rRNAs), transfer RNAs (tRNAs), and regulatory ncRNAs. Also, regulatory ncRNAs can be divided into two subtypes: small non-coding RNAs with less than 200 nucleotides and long non-coding RNAs with more than 200 nucleotides. MicroRNAs (miRNAs), P-Element induced wimpy testis (PIWI)-interacting RNA (piRNAs), small interfering RNA (siRNAs), and small nucleolar RNA (snoRNA) are four kinds of RNAs classified as small non-coding RNAs which differ from each other in many aspects including their biogenesis pathways [5-7].

As a member of sncRNAs, piRNAs have 24 to 32 nucleotides. A trial investigating how Stellate proteincoding gene repeats are silenced in the Drosophila melanogaster male germ line, helped to discover the existence of piRNAs for the first time [8]. These RNAs were called repeat-associated small interfering RNAs (rasiRNAs) at first, but then, after revealing their interaction with PIWI proteins they were named piRNAs $[9,10]$. Recent studies have shown that sncRNAs can take part in the regulation of gene expression and thereby, they can be key players 
in many physiological and pathological activities in the body. This feature is possible through RNA interference, RNA modification, and spliceosomal involvement and as a result, they might be involved in several diseases such as cancer $[2,6,11]$. piRNAs, as a class of small noncoding RNAs, also are participating in regulation of genes and proteins; but generally, it's not easy to specify their exact functions; because not only there is a great variety in piRNAs' sequences but also their activities can be different between species [12]. Other functions of these RNAs include silencing of transposon elements (TEs), epigenetic regulation, reorganization of the genome, spermatogenesis, and germ stem-cell maintenance [5].

In addition, PIWI proteins enhance the methylation of DNA and thereby, operate on the chromatin level and they can also compose some histone marks which repress the transcription of TEs [1]. PIWI proteins are a family of proteins encoded by the Drosophila piwi gene and are identified in gonad and germline development along with transposon silencing. Both mice and Drosophila are identified to express three classes of PIWI proteins while humans are able to express four types: HIWI, HILI, HIWI2, and PIWIL3 [13].

Some of these properties can provide an idea that piRNAs are associated with some cancer hallmarks containing cell proliferation, apoptosis, metastasis, and invasion [5].

Colorectal cancer (CRC) is a major cause of morbidity and mortality in both men and women around the world [14]. According to world cancer research fund, this cancer is listed as the third common cancer after lung and breast cancer with 1.8 million new cases reported in 2018 [15]. Moreover, developed countries have a higher incidence rate for CRC. Possible risk factors for this kind of cancer are overweight, extravagant alcohol drinking, having a CRC family history, inflammatory bowel disease (IBD), cigarette-smoking, and consuming processed red meat $[16,17]$. In contrast, there are also some factors which can cause a reduction in CRC risk such as physical exercise, hormone therapy in postmenopausal women, and aspirin/NSAID use, as well as, fruit and vegetable consumption [18]. In addition, some studies declared a greater CRC risk for men than women [19, 20].

This review is an attempt for providing more effective diagnostic and/or prognostic and therapeutic approaches for decreasing the global burden of colorectal cancer and preventing more patients from suffering.

\section{PiRNAs biogenesis}

According to investigations in this field, piRNAs are classified into three subclasses based on the variety of origins they are derived from. Transposon-derived, mRNAderived, and lncRNA-derived are these subclasses. The first type of these RNAs is composed of the sense piRNAs along with the antisense ones. The second type is processed and originate from the 3' untranslated regions (UTRs) while the third type is originated from the whole transcript [21]. The initiation of piRNA biogenesis is conducted by Pol II which transcribes these RNAs from their clusters mostly observed in pericentromeric and telomeric heterochromatin regions [22]. In mammalian, there are two class of single-strand clusters known for piRNAs based on the direction of their transcription: unidirectional and bidirectional [22, 23]. After transcription, piRNA precursors ought to be transferred into the cytoplasm in order to go through some alterations. This transportation is confirmed to be possible by $\mathrm{Nxf1}$ and Nxt1 in Drosophila [24].

One of the reasons that piRNA is quite different from other types of sncRNAs is that its biogenesis is managed independent from RNase III Dicer, an enzyme involved in the biogenesis of other sncRNAs [23, 25]. In contrast to the several differences between piRNAs and other types of sncRNAs, post-transcriptional processes are common between these RNAs which are required for piRNAs to become mature. piRNA maturation is possible through two different mechanisms after transcription: the primary processing pathway and the Ping-Pong amplification loop (Fig. 1) [26]. In our knowledge, both of these pathways are essential for creation a powerful defense against the transposons [8]. However, the pingpong pathway is utilized only in germline cells when the former pathway is detected in both germline and somatic cells [13].

\section{The primary processing pathway}

There is limited evidence regarding the details of this pathway (especially in mammalians) and there is a great need for further investigations in this field.

In Drosophila, the primary mechanism is executed by an enzyme termed ribo-endonuclease Zucchini which cleaves the initial transcript of piRNA [27]. The location of this enzyme is revealed to be on the mitochondrial surface. In the following steps of this pathway some granules named $\mathrm{Yb}$ bodies are participating which encompass fs(1) $\mathrm{Yb}(\mathrm{Yb})$, Armitage (Armi), Vreteno (Vret), and Sister of $\mathrm{Yb}(\mathrm{SoYb})$ [28-30]. After that, the 3'portion is merged with PIWI proteins and then, its size is reduced to a final length by a 3' to 5' exonuclease. The hydroxyl group of the 3 ' end of this piRNA ought to be methylated as a result of a methyltransferase activity named Hen 1 . While all these are happening, the other end of the transcript (5'end) represents a strong bias for uridine residue [31]. At the end of this process, the piRNA with the final length binds to PIWI proteins in order to form a piRNA-PIWI complex. This complex has the responsibility of activating the 


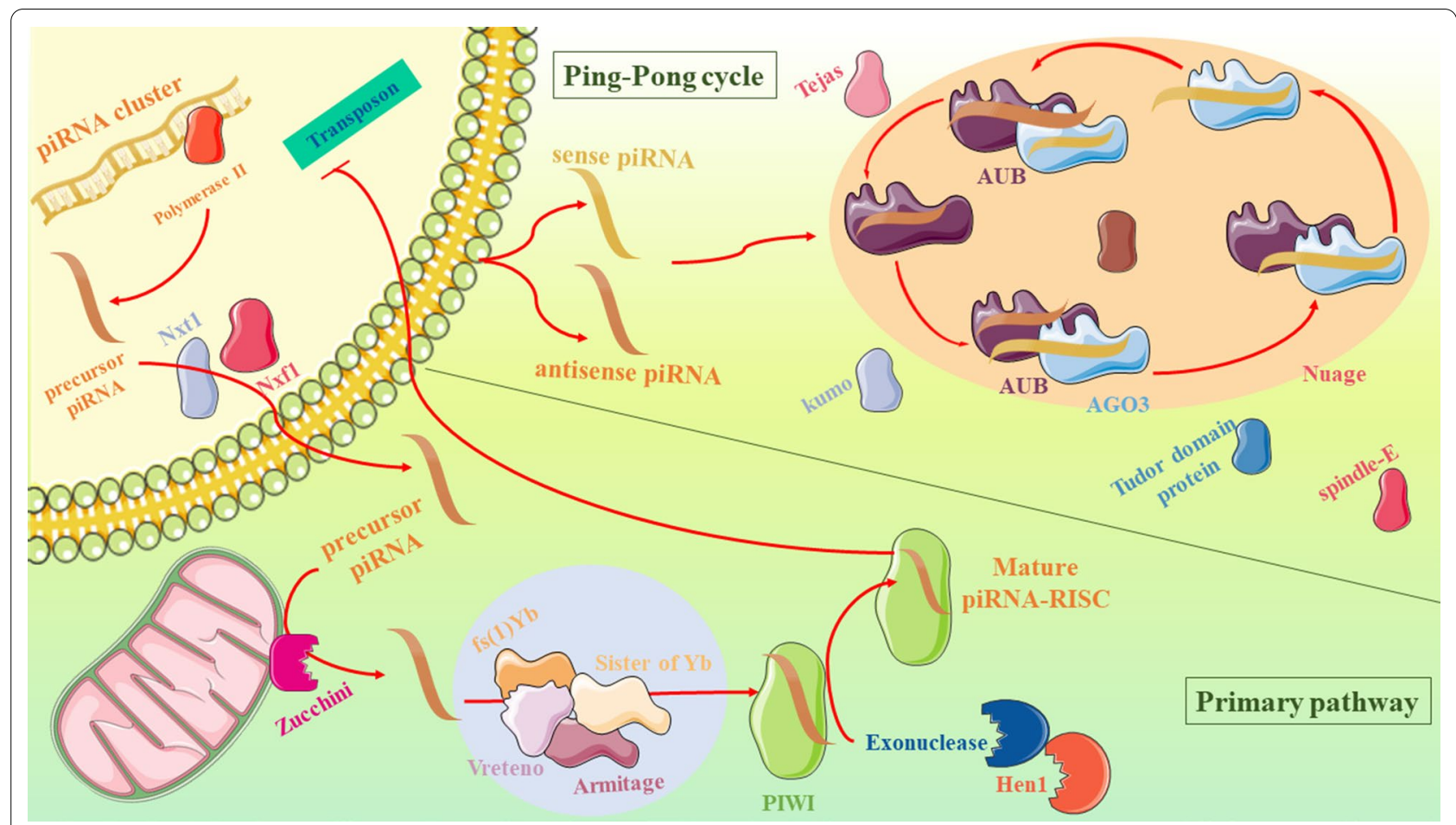

Fig. 1 piRNA biogenesis. After piRNA transcription, their precursors are transferred into the cytoplasm in order to become mature through either the primary pathway or the ping-pong cycle

silencer machinery and thereby, inhibiting the transcription of its target gene, but all this is only possible if this complex travels back to the nucleus. Through this mechanism, piRNAs are able to install transcriptionally silent heterochromatin and by means of that they can affect TEs [32].

\section{The Ping-Pong amplification loop}

The importance of this mechanism is related to the necessity of amplifying primarily generated piRNAs located in the cytoplasm [31]. Generally, there are three subtypes of Argonaute protein family: AUB, AGO3 and PIWI [33] which AUB and AGO3 take part in the Ping-Pong mechanism in spite of the primary synthesis. After binding of antisense piRNAs to AUB, a complex is formed which is known as piRNA-AUB complex. AUB uses its slicer feature on the piRNA and provides a cleaved piRNA which would act as a substrate for AGO3. For continuing the cycle, a piRNA-AGO3 complex is formed in order to target the antisense RNAs and thereby, provide substrates for AUB. To summarize, piRNA molecules can be built in the cytoplasm from a substrate provided by another functional piRNA's product based on an amplification mechanism [22, 34]. Interestingly, all of these events are occurring in a perinuclear structure named nuage. Furthermore, previous researches indicate a role for Zucchini and Nibbler (Nbr), a $3^{\prime}$-to- $5^{\prime}$ exonuclease, in this process which are mostly responsible for the $3^{\prime}$ end formation of secondary piRNAs $[35,36]$. In addition, there are some other ingredients which aid the production of secondary piRNAs; for instance, vasa, tejas, kumo, spindle-E, and Tudor domain proteins [37-39].

This pathway is beneficial for not only amplifying piRNAs but also for silencing the TEs [22].

Accumulative evidence indicates that in mice, piRNA biogenesis through spermatogenesis is not related to this mechanism. However, signs of Ping-Pong are mostly observed in zebrafish, melanogaster, and very primitive animals like sponges [40].

\section{Functions of PIWI proteins and their associated RNAs}

A number of functions are attributed to these non-coding RNAs which are discussed briefly in this section.

\section{Silencing of transposons or TEs}

In most eukaryotes, RNA interfering (RNAi) or RNA silencing appears to be one of the essential pathways in gene regulation. RNA silencing pathway is based on the creation of small RNAs with 20-31 nucleotides; This small RNA induces the formation of a silencing complex which is called RISC (RNA-induced silencing complex) 
[1]. The task of piRNAs on transposon silencing is managed by the RISK complex. This complex binds to PIWI proteins and thereby, leads them to their transposon target and that is the reason why an elevation in transposon expression can be a result of the reduced or absent gene expression of PIWI proteins [41]. In our knowledge, TEs are high potent DNA sequences known for causing harmful effects on their host [42]. TEs' damaging impacts rely on their roles in genomic instability and diversity [43, 44], gene dysregulation, harmful mutations, and chromosome rearrangement [45]. The non-long terminal repeat (non-LTR) TEs can be divided into two groups encompassing the long-interspersed elements (LINEs) and the short-interspersed ones (SINEs). Breast, colon, and ovarian cancers as well as leukemias are some diseases in which non-LTR families like L1, SVA, and Alu are involved [46].

piRNA-RISC complex silences these mobile sequences through different mechanisms including chromatin remodeling, histone modification, and targeting the RNAs transcribed from TE loci [47-49]. One of the mechanisms is managed through histone 3 lysine 9 (H3K9me3). Methylation of H3K9me3 on chromatin is one of the reasons why heterochromatin is formed in loci of transposons [50]. Heterochromatin formation can also be the result of the binding of Piwi proteins to both piRNAs and Panoramix/Silencio (Panx). Panx is a cofactor for Piwi which makes the heterochromatinization possible through recruiting the histone modification enzymes [51]. Linker histone H1 is mediating the chromatin remodeling function of piRNAs. This histone is involved in both chromatin three-dimensional structure and transposon expression [52].

\section{Epigenetic activating}

Explorations on the somatic cells of Drosophila revealed that PIWI proteins and their associated piRNAs are participating in epigenetic processes. PIWI and piRNA function together as a complex when are bind to each other. The role of this complex is sequence-recognition which calls up the effectors of epigenetic including heterochromatin protein 1a (HP1a) to a definite site of genome and by that means, accomplishes epigenetic regulation [53].

PIWI-RNA epigenetic activator role was well-understood when it was discovered that the expression of 3R-TAS requires PIWI in a dose-dependent manner. 3R-TAS is a telomere-associated sequence locating on the right arm of chromosome 3. PIWI by the means of binding to both 3R-TAS and a piRNA mapped to 3R-TAS, executes its function. Any mutation in PIWI results in losing euchromatic histone modifications, which is an important mechanism in regulating the gene expression [54]. In addition, another mechanism is how
piRNAs conscript PIWI proteins and H3K9me3 to the promoter region to create large complexes which conduct transcriptional silencing. These complexes cover transcriptional start sites or TSS and cause the inhibition of RNA polymerase II to recognize the TSS which results in silencing the expression of the target gene [55].

\section{Gene and protein regulator}

Another functionality of this non-coding RNAs is how they can act as a host gene and a regulator of protein. For instance, piR_015520 is in intron 1 of the human melatonin receptor $1 \mathrm{~A}$ gene which its expression is dysregulated in cancerous cells of prostate. PiR_015520 has been observed to have negative regulating effects on the expression of melatonin receptor 1A gene (MTNR1A) by binding to its genomic region. In addition, overexpression of piR_015520 results in a repression of MTNR1A expression in a concentration-dependent manner [56]. This information revealed that modifications in the levels of piRNA expression could impact on the expression levels of the gene where the piRNA is settled and this can raise our understanding of piRNAs as an expression regulator.

\section{Other functions}

There are also some other roles that can be attributed to piRNAs such as buffering against phenotypic variations and genome rearrangement. Genome rearrangement of somatic elimination is a process that occurs in the zygotic genome of the daughter cells due to the production of a new and partial somatic genome which will be a replacement for parental germ line genome. This replacement hinders the transcription of parental germ line genome in the result of macronuclei after conjugation [57]. Moreover, piRNAs also take part in spermatogenesis, germ stem cell maintenance, and etc. [5]. It is obvious that piRNAs have widespread roles in different process of our cells but still, further investigations might give us novel insights on their functions.

\section{The role of piRNAs and PIWI proteins in cancer}

One of the differences between piRNAs and miRNAs is that piRNAs are not complementary to the mRNA of potential target genes. This shows that this kind of RNAs may have a role in epigenetic regulation instead of post-transcriptional regulation for controlling different biologic incidents such as cancer [58,59]. Epigenetic global alterations of cancers include DNA hypomethylation, histones hypoacetylation, and gene-specific DNA hypermethylation which lead to oncogene activation and tumor suppressor silencing $[60,61]$. In general, the profile of the expressed piRNAs in a particular tissue plays a role in tissue identification by providing a unique signature 
for that tissue. PiRNAs regulate genes epigenetically and so they determine how many genes should be active at a time in a specific cell $[62,63]$. Consequently, these RNAs can also be known as cancer-specific signatures because, in cancer cells, global hypomethylation and focal hypermethylation occurs and thereby, piRNAs are expressed abnormally in cancer cells $[64,65]$. Some research has shown that despite of the wide involvement of piRNAs in cancer cells, only a small amount of them is expressed in somatic cells [66]. Overall, Martinez et al. [66] revealed that piRNAs have some functions in cell proliferation, apoptosis, metastasis, and invasion. Moreover, the family of PIWI proteins has some pivotal roles in self-renewal mechanism of stem and germ cells, and silencing of the RNA and translational regulation in diverse organisms [67-69]. This family contains four subtypes which any of them has a different role in cancer cells (PIWIL1 or HIWI, PIWIL2, PIWIL3, and PIWIL4) [70]. In the next sections, we are going to discuss the role of piRNAs as well as PIWI proteins in cancer cells.

\section{Cell proliferation and apoptosis}

Several studies are conducted on different kinds of cancers to show that piRNAs can cause the inhibition of cell proliferation in cancer cells. Chu et al. [71] found that Over-expression of piRABC (a kind of piRNA) upregulated the TNFSF4 protein and thereby, caused the inhibition of bladder cancer cell proliferation, colony formation, and also promotion of cell apoptosis. Yan et al. [72] investigated piRNA-823 in multiple myeloma patients $(\mathrm{MM})$ and observed a reduction in regulators of cell cycle and the expression of proteins involved in apoptosis and the inhibition of tumorigenicity in vivo and in vitro. This trial also revealed that piRNA-823 can also reduce global methylation in DNA and re-expression of a methylation-silenced tumor suppressor. Furthermore, Jacobs et al. [73] investigated the role of piR-598 in glioma and found that this piRNA effects cell survival and increases the viability of glioma cells and the formation of the colony and as a result, it aggressively elevates cell proliferation. Moreover, also HIWI or PIWIL1 [74-81], PIWIL2 [82, 83], and PIWIL4 [84,85] (members of PIWI subfamily) have been proven to play important roles in cell proliferation and apoptosis in several types of cancers.

\section{Cancer cell metastasis and invasion}

Some researchers have focused on the roles of piRNAs in some cancers such as breast cancer [86-88], gastric cancer [89, 90], clear cell renal cell carcinoma (ccRCC) [91], and hepatocellular carcinoma [92] and their works are great evidence to prove that the piRNAs have the potential effects to block the metastasis and invasion of cancer cells. In our knowledge, blocking cancer metastasis in different types of cancers is done by diverse piRNAs but overall, we can say that all these piRNAs are doing their duty by two mechanisms: gene methylation and AKT pathway phosphorylation (which the second mechanism is only reported in hepatocellular carcinoma). In addition, some other studies have demonstrated that some members of the PIWI subfamily can influence metastasis and invasion in cancer cells by regulating MMP- 2 and MMP-9, although further trials are needed for understanding the exact mechanism. A line of research on on HIWI has revealed a relationship between this protein and cancers such as epithelial ovarian cancer [93], glioma [80], and hepatocellular carcinoma [75]. Moreover, PIWIL2 [94] and PIWIL4 [84] also has impacts on metastasis (particularly PIWIL2 which has a role in colon cancer). Taking together, this evidence revealed that piRNAs and PIWI proteins have crucial roles in inhibiting another cancer hallmark: metastasis.

\section{PiRNA and CRC}

Growing evidence revealed that colorectal cancer is a heterogeneous disorder. Mutations of the genome and epigenetic alterations [containing DNA methylation, histone modification and non-coding RNAs (ncRNAs)] can activate oncogenes and inactivate tumor-suppressor genes and thereby, cause colorectal cancer [95-99]. Currently, some dysregulated piRNAs have been found in tumor tissues. In a general manner, gene expression, epigenetic processes, differentiation, proliferation, migration, and apoptosis of the cells, transcriptional regulation, post-transcriptional regulation, organ regeneration, and human disorders are the fields in which piRNAs are involved [100-103]. In the past few years, the functional mechanism of piRNAs in cancers has been considered and most of these studies suggested an epigenetic regulation role for these non-coding RNAs. Furthermore, a few studies also discovered that piRNAs regulate mRNA expression through binding to the $3^{\prime} \mathrm{UTR}$ of mRNAs. A recent study reported that piRNAs are able to bind to introns of a pre-mRNA and their binding results in the deterioration of targeted pre-mRNA through nuclear exosomes [104]. On top of that, Watanabe, et al. [105] indicated that piRNAs may suppress the expression levels of mRNAs by harboring transposon sequence in the 3'UTR or 5'UTR region. In addition, piRNAs may also function as natural antisense molecules which bind to $\mathrm{CD}$ regions of genes and thereby, they target these genes or target 3'UTR by acting as siRNAs [26, 105-107].

When all of these studies focused on the regulation of gene expression, Yin et al. [108] surprisingly found that piRNAs regulated the post-translational alteration and activity of HSF1 via interaction with this protein. This 
study gave us a new perception about the way that piRNAs function through. In CRC, involved piRNAs are including piR-651, piR-54,878, piR59056, piR-62,701, piR-823, piR-015,551, piR-54265, and piR-1245 which all are summarized in Table 1. Generally, STAT3 pathway is an oncogenic signaling that causes anti-apoptotic and prometastatic effects $[109,110]$. For the first time, an investigation has revealed that piR-54265 expression and its interaction with PIWIL2 protein mediates the formation of PIWIL2/STAT3/p-SRC complex activating STAT3 by phosphorylation. This study suggested that over-expression and/or abnormal activation of STAT3 are enhanced by piR-54265 [111]. In addition, $85.7 \%$ sensitivity and $65.1 \%$ specificity of this piRNA in CRC diagnosis is suggesting that is has the potential to take the place of current diagnostic markers [112]. Mai et al. [111] also found that this piRNA can also be a new therapeutic target for CRC and it can be used to predict the response of cancer cells to chemotherapy in CRC patients. In another study, Weng et al. [113] identified 9 cancer-related genes (including ATF3, BTG1, DUSP1, FAS, NFKBIA, UPP1, SESN2, TP53INP1 and MDX1) which were functionally relevant to $\mathrm{CRC}$. These genes had functions in key tumor suppressive pathways and their expression was associated with piR1245 expression. The authors concluded that this piRNA can be considered as a prognostic biomarker in CRC.

PiR-823 is one of the most important piRNAs because of its roles in diverse types of cancer. According to the results of a research, piR-823 elevated the amounts of HSF1 that is a common transcriptional factor for heat shock proteins (HSPs) family and by that, it enhances the expression of all of the HSP family except for HSP90 [114]. HSPs are classified into four groups including HSP27, HSP60, HSP70 and HSP90 [115]. This protein family is an important factor in several different cancers (including CRC) because of their association with an increased rate of cell proliferation, decreased apoptosis index, malignancy and poor prognosis [116-118]. Moreover, this RNA is increased expression is related to the advanced stages of CRC with $83.3 \%$ sensitivity and $89.3 \%$ specificity [119]. Similarly, increased serum levels of piR24000 is also detected to be associated with CRC metastasis and higher stages [120].

In addition, Koduru et al. [121] did some comprehensive analysis on ncRNAs and they identified that there are some differences between the expression of these RNAs in different stages of CRC. Their result identified six piRNAs with statistically significant expression; Two piRNAs with upregulation in both tumor and metastasis groups; three up-regulated piRNA (including piR-hsa-25447, piRhsa-23992, and piR-hsa-1043) and a down-regulated one (piR-hsa-28876) in tumor versus benign group; and in the metastasis versus benign group there were 22 up-regulated piRNA and 5 down-regulated ones. piR-5937 and piR-28876 are also two other piRNAs which are approved to be deregulated in CRC patients in comparison to healthy individuals [122].

Interestingly, a recent study shows that piRNAs are also useful for an earlier detection. piR-020619 and piR020450 are observed to be increased even in early stages of CRC with a small sized tumor. Furthermore, these piRNAs are not detected in other cancer patients and therefore, they are specific to CRC [123].

According to the expression profiles of cancer-typespecific piRNAs we think that being a potential diagnostic biomarker for cancer might be a feature of piRNAs which have been ignored. Besides, piRNAs have some characteristics which make them a proper candidate for being a prognostic biomarker for cancer. PiRNAs are small molecules so they can't be degraded so easily despite the long RNAs and also this feature allows them to pass through the membrane of the cell easier than other types. Therefore, piRNAs are more detectable in samples obtained from cancer patients [5].

Table 1 Experimental studies that investigated the role of piRNAs in colorectal cancer

\begin{tabular}{lllll}
\hline PiRNA & Model & Expression & Function & References \\
\hline PiR-823 & In vitro & Up-regulated & Associated with the expression of HSP family & [108] \\
PiR-54265 & In vitro & Up-regulated & Activating STAT3 signaling & {$[111]$} \\
PiR-651 & In vitro & Up-regulated & Associated with T stage, metastasis & {$[91]$} \\
PiR-54,878 & In vitro & Up-regulated & Associated with recurrence-free survival & {$[90]$} \\
PiR-59056 & In vitro & Up-regulated & Associated with recurrence-free survival & {$[90]$} \\
PiR-62701 & In vitro & Up-regulated & Associated with recurrence-free survival & {$[90]$} \\
PiR-015551 & In vitro & Down-regulated & Associated with LNC00964-3 expression level & [71] \\
PiR-1245 & In vitro & Down-regulated & Associated with advanced and metastatic disease & {$[113]$} \\
\hline
\end{tabular}




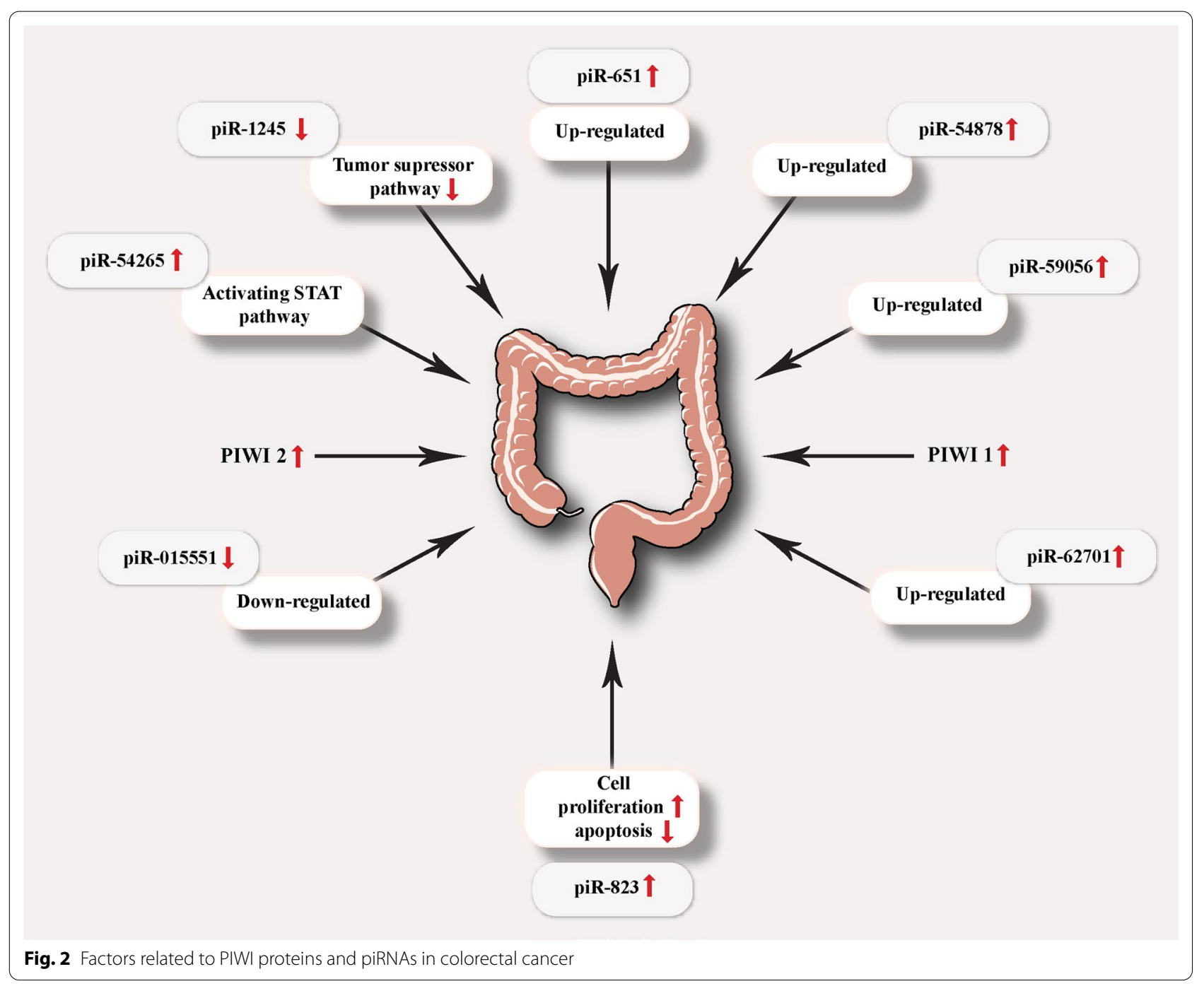

\section{PIWI proteins and CRC}

To date, there is a small amount of examination evaluating the expression of PIWI proteins in CRC. HIWI the first member of this family which has an important duty in regulating the renewal of stem cells has been shown to have over-expressed in some types of cancers including CRC [124]. Yang et al. [125] confirmed that there is an over-expression of HIWI in CRC leading to an enhancement in global DNA methylation and thereby, promoting the proliferation of CRC cells. In addition, Zeng et al. [126] found that HIWI can also be a biomarker for the prognosis of CRC particularly in patients at an early stage of disease or for whom without any lymph node metastasis. Moreover, a study about PIWIL2 demonstrated that PIWIL2, as well as PIWIL1, can be a biomarker for CRC because of its higher expression in this kind of cancer [127]. Another immunohistochemical trial revealed that all of the members of this family are overexpressed in
CRC and they also found that PIWIL2 and PIWIL4 can be used as biomarkers; the former for early diagnosis and the latter for advanced tumors with distant metastasis [128]. In addition, a research found that the combination of sncRNAa with a nano-size polymer carrier might be a new therapeutic tool for colorectal cancer [129].

\section{Conclusions}

PiRNAs are a group of small-noncoding RNAs which function by forming complexes with PIWI protein family. They provide a system that protects the genome against the expression of transposon elements. After revealing their role in inducing apoptosis and preventing the cell proliferation, this thought was formed that they may also be involved in cancer. Till now, several researches are done due to find a therapeutic or diagnostic approach relying on the amounts of piRNAs in different types of 
cancer. Colorectal cancer, considering its importance because of the high number of reported cases annually, is one of this cancer on which a few investigations has been conducted. Accumulative evidence expresses that PIWI proteins and their related RNAs (piRNAs) can be used only for diagnostic or prognostic purposes in this cancer and till now, no therapeutic effects are discovered for them but further investigations might improve our knowledge on whether they can be used for therapeutic purposes or not (Fig. 2). It worth to mention that a trial declared that combination of interleukin-6, piRNA, and a kind of micro RNA can lead to the transformation of cancer cells into CD4+ cells and therefore, it can be a useful procedure, in coming years, as combined therapy for colorectal cancer. Despite these advantageous, a problem stands in the way of detecting piRNA in patients' serums: identifying the fragments of other ncRNAs instead of actual piRNAs. Recently, using miscellaneouspiRNAs (m-piRNAs) has been suggested as a solution to this problem but still, this method is not the definite answer [130].

Overall, the study of these RNAs in colorectal cancer is still in its infancy and there is a great number of obstacles in the way of establishing new piRNA-based prognostic or diagnostic procedures for being used in clinics.

\begin{abstract}
Abbreviations
NcRNA: Non-coding RNA; rRNA: Ribosomal RNA; tRNA: Transfer RNA; miRNA: Micro RNA; piRNA: PIWI- associated RNA; siRNA: Small interfering RNA; snoRNA: Small nuclear RNA; rasiRNA: Repeat-associated small interfering RNA; TE: Transposon element; CRC: Colorectal cancer; IBD: Inflammatory bowel disease; UTR: Untranslated region; RNAi: RNA interfering; RISC: RNA-induced silencing complex; LTR: Long terminal repeat; LINE: Long interspersed element; SINE: Small interspersed element; HP1a: Heterochromatin protein 1a; MM: Multiple myeloma; ccRCC: Clear cell renal cell carcinoma; HSP: Heat shock protein; TSS: Transcriptional start site.
\end{abstract}

\section{Acknowledgements}

Not applicable.

\section{Authors' contributions}

SMM and ZA contributed in conception, design and drafting of the manuscript. FS contributed in data collection and manuscript drafting. All authors approved the final version for submission. All authors read and approved the final manuscript.

\section{Funding}

Not applicable.

\section{Availability of data and materials \\ Not applicable.}

\section{Declarations}

Ethics approval and consent to participate Not applicable.

Consent for publication

Not applicable.

\section{Competing interests}

The authors declare no conflict of interest.

Received: 13 December 2019 Accepted: 19 June 2021

Published online: 30 June 2021

\section{References}

1. Watson CN, Belli A, Di Pietro V. Small non-coding RNAs: new class of biomarkers and potential therapeutic targets in neurodegenerative disease. Front Genet. 2019;10:364.

2. Hombach S, Kretz M. Non-coding RNAs: classification, biology and functioning. Adv Exp Med Biol. 2016;937:3-17.

3. Palazzo AF, Lee ES. Non-coding RNA: what is functional and what is junk? Front Genet. 2015;6:2.

4. Genomics PE. ENCODE project writes eulogy for junk DNA. Science. 2012;337(1159):61.

5. Han YN, Li Y, Xia SQ, Zhang YY, Zheng JH, Li W. PIWI proteins and PIWI-interacting rna: emerging roles in cancer. Cell Physiol Biochem. 2017:44:1-20

6. Chen $\mathrm{H}, \mathrm{Xu} \mathrm{Z}$, Liu D. Small non-coding RNA and colorectal cancer. J Cell Mol Med. 2019;23:3050-7.

7. Ghildiyal M, Zamore PD. Small silencing RNAs: an expanding universe. Nat Rev Genet. 2009;10:94-108.

8. Siomi MC, Sato K, Pezic D, Aravin AA. PIWI-interacting small RNAs: the vanguard of genome defence. Nat Rev Mol Cell Biol. 2011;12:246-58.

9. Aravin AA, Lagos-Quintana M, Yalcin A, Zavolan M, Marks D, Snyder B, et al. The small RNA profile during Drosophila melanogaster development. Dev Cell. 2003;5:337-50.

10. Theurkauf WE, Klattenhoff C, Bratu DP, McGinnis-Schultz N, Koppetsch BS, Cook HA. rasiRNAs, DNA damage, and embryonic axis specification. Cold Spring Harb Symp Quant Biol. 2006;71:171-80.

11. Romano G, Veneziano D, Acunzo M, Croce CM. Small non-coding RNA and cancer. Carcinogenesis. 2017;38:485-91.

12. Wang G, Reinke VAC. elegans Piwi, PRG-1, regulates 21 U-RNAs during spermatogenesis. Curr Biol. 2008;18:861-7.

13. Iwasaki YW, Siomi MC, Siomi H. PIWI-interacting RNA: Its biogenesis and functions. Annu Rev Biochem. 2015;84:405-33.

14. Haggar FA, Boushey RP. Colorectal cancer epidemiology: incidence, mortality, survival, and risk factors. Clin Colon Rectal Surg. 2009:22:191-7.

15. World Cancer Research Fund. Global cancer incidence: both sexes. 2018.

16. Keum N, Giovannucci E. Global burden of colorectal cancer: emerging trends, risk factors and prevention strategies. Nat Rev Gastroenterol Hepatol. 2019;16:713-32.

17. Song M, Chan AT, Sun J. Influence of the gut microbiome, diet, and environment on risk of colorectal cancer. Gastroenterology. 2020;158:322-40.

18. Johnson CM, Wei C, Ensor JE, Smolenski DJ, Amos Cl, Levin B, et al. Meta-analyses of colorectal cancer risk factors. Cancer Causes Control. 2013:24:1207-22.

19. Giovannucci E. Obesity, gender, and colon cancer. Gut. 2002;51:147.

20. Ning Y, Wang L, Giovannucci EL. A quantitative analysis of body mass index and colorectal cancer: findings from 56 observational studies. Obes Rev. 2010;11:19-30

21. Thomson T, Lin H. The biogenesis and function of PIWI proteins and piRNAs: progress and prospect. Annu Rev Cell Dev Biol. 2009:25:355-76.

22. Yamashiro H, Siomi MC. PIWI-interacting RNA in drosophila: biogenesis, transposon regulation, and beyond. Chem Rev. 2018;118:4404-21.

23. Girard A, Sachidanandam R, Hannon GJ, Carmell MA. A germlinespecific class of small RNAs binds mammalian Piwi proteins. Nature. 2006;442:199-202.

24. Muerdter F, Guzzardo PM, Gillis J, Luo Y, Yu Y, Chen C, et al. A genomewide RNAi screen draws a genetic framework for transposon control and primary piRNA biogenesis in Drosophila. Mol Cell. 2013;50:736-48. 
25. Aravin A, Gaidatzis D, Pfeffer S, Lagos-Quintana M, Landgraf P, lovino N, et al. A novel class of small RNAs bind to MILI protein in mouse testes. Nature. 2006:442:203-7.

26. Weick EM, Miska EA. piRNAs: from biogenesis to function. Development. 2014;141:3458-71.

27. Nishimasu H, Ishizu H, Saito K, Fukuhara S, Kamatani MK, Bonnefond L, et al. Structure and function of Zucchini endoribonuclease in piRNA biogenesis. Nature. 2012;491:284-7.

28. Saito K, Ishizu H, Komai M, Kotani H, Kawamura Y, Nishida KM, et al. Roles for the Yb body components Armitage and Yb in primary piRNA biogenesis in Drosophila. Genes Dev. 2010;24:2493-8.

29. Zamparini AL, Davis MY, Malone CD, Vieira E, Zavadil J, Sachidanandam $\mathrm{R}$, et al. Vreteno, a gonad-specific protein, is essential for germline development and primary piRNA biogenesis in Drosophila. Development. 2011;138:4039-50.

30. Qi H, Watanabe T, Ku H-Y, Liu N, Zhong M, Lin H. The Yb body, a major site for Piwi-associated RNA biogenesis and a gateway for Piwi expression and transport to the nucleus in somatic cells. J Biol Chem. 2011;286:3789-97.

31. Brennecke J, Aravin AA, Stark A, Dus M, Kellis M, Sachidanandam R, et al. Discrete small RNA-generating loci as master regulators of transposon activity in Drosophila. Cell. 2007;128:1089-103.

32. Luteijn MJ, Ketting RF. PIWI-interacting RNAs: from generation to transgenerational epigenetics. Nat Rev Genet. 2013;14:523-34.

33. Gunawardane LS, Saito K, Nishida KM, Miyoshi K, Kawamura Y, Nagami T, et al. A slicer-mediated mechanism for repeat-associated siRNA $5^{\prime}$ end formation in Drosophila. Science. 2007;315:1587-90.

34. Ross RJ, Weiner MM, Lin H. PIWI proteins and PIWI-interacting RNAs in the soma. Nature. 2014;505:353-9.

35. Feltzin VL, Khaladkar M, Abe M, Parisi M, Hendriks GJ, Kim J, et al. The exonuclease Nibbler regulates age-associated traits and modulates pi RNA length in D rosophila. Aging Cell. 2015;14:443-52.

36. Mohn F, Handler D, Brennecke J. piRNA-guided slicing specifies transcripts for Zucchini-dependent, phased piRNA biogenesis. Science. 2015:348:812-7.

37. Patil VS, Kai T. Repression of retroelements in Drosophila germline via piRNA pathway by the Tudor domain protein Tejas. Curr Biol. 2010;20:724-30

38. Anand A, Kai T. The tudor domain protein kumo is required to assemble the nuage and to generate germline piRNAs in Drosophila. EMBO J. 2012;31:870-82.

39. Ott KM, Nguyen T, Navarro C. The DExH box helicase domain of spindle-E is necessary for retrotransposon silencing and axial patterning during Drosophila oogenesis. G3: Genes, Genomes, Genetics. 2014. 4:2247-2257.

40. Beyret E, Liu N, Lin H. piRNA biogenesis during adult spermatogenesis in mice is independent of the ping-pong mechanism. Cell Res. 2012;22:1429-39.

41. Aravin AA, Sachidanandam R, Bourc'his D, Schaefer C, Pezic D, Toth KF, et al. A piRNA pathway primed by individual transposons is linked to de novo DNA methylation in mice. Mol Cell. 2008;31:785-99.

42. O'Donnell KA, Boeke JD. Mighty Piwis defend the germline against genome intruders. Cell. 2007:129:37-44.

43. Kazazian HH Jr. Mobile elements: drivers of genome evolution. Science. 2004;303:1626-32.

44. Cordaux R, Batzer MA. The impact of retrotransposons on human genome evolution. Nat Rev Genet. 2009;10:691-703.

45. Chenais B. Transposable elements and human cancer: a causal relationship? Biochim Biophys Acta. 2013;1835:28-35.

46. Konkel MK, Batzer MA. A mobile threat to genome stability: The impact of non-LTR retrotransposons upon the human genome. Semin Cancer Biol. 2010;20:211-21.

47. Klenov MS, Lavrov SA, Korbut AP, Stolyarenko AD, Yakushev EY, Reuter $M$, et al. Impact of nuclear Piwi elimination on chromatin state in Drosophila melanogaster ovaries. Nucleic Acids Res. 2014;42:6208-18.

48. Le Thomas A, Rogers AK, Webster A, Marinov GK, Liao SE, Perkins EM, et al. Piwi induces piRNA-guided transcriptional silencing and establishment of a repressive chromatin state. Genes Dev. 2013;27:390-9.

49. Mukandavire Z, Liao S, Wang J, Gaff H, Smith DL, Morris JG. Estimating the reproductive numbers for the 2008-2009 cholera outbreaks in Zimbabwe. Proc Natl Acad Sci. 2011;108:8767-72.
50. Sienski G, Dönertas D, Brennecke J. Transcriptional silencing of transposons by Piwi and maelstrom and its impact on chromatin state and gene expression. Cell. 2012;151:964-80.

51. Yu Y, Gu J, Jin Y, Luo Y, Preall JB, Ma J, et al. Panoramix enforces piRNAdependent cotranscriptional silencing. Science. 2015;350:339-42.

52. Iwasaki YW, Murano K, Ishizu H, Shibuya A, Iyoda Y, Siomi MC, et al. Piwi modulates chromatin accessibility by regulating multiple factors including histone $\mathrm{H} 1$ to repress transposons. Mol Cell. 2016;63:408-19.

53. Lin $\mathrm{H}$, Yin $\mathrm{H}$, editors. A novel epigenetic mechanism in Drosophila somatic cells mediated by Piwi and piRNAs. Cold Spring Harbor symposia on quantitative biology; 2008. Cold Spring Harbor Laboratory Press.

54. Yin $\mathrm{H}$, Lin $\mathrm{H}$. An epigenetic activation role of Piwi and a Piwi-associated piRNA in Drosophila melanogaster. Nature. 2007:450:304.

55. Meller VH, Joshi SS, Deshpande N. Modulation of chromatin by noncoding RNA. Annu Rev Genet. 2015;49:673-95.

56. Esposito T, Magliocca S, Formicola D, Gianfrancesco F. piR_015520 belongs to Piwi-associated RNAs regulates expression of the human melatonin receptor 1A gene. PLoS ONE. 2011;6:e22727.

57. Schoeberl UE, Mochizuki K. Keeping the soma free of transposons: programmed DNA elimination in ciliates. J Biol Chem. 2011;286:37045-52.

58. Kim VN. Small RNAs just got bigger: Piwi-interacting RNAs (piRNAs) in mammalian testes. Genes Dev. 2006;20:1993-7.

59. Wang QX, Zhu YQ, Zhang H, Xiao J. Altered MiRNA expression in gastric cancer: a systematic review and meta-analysis. Cell Physiol Biochem. 2015;35:933-44.

60. Feldman N, Gerson A, Fang J, Li E, Zhang Y, Shinkai Y, et al. G9amediated irreversible epigenetic inactivation of Oct-3/4 during early embryogenesis. Nat Cell Biol. 2006;8:188-94.

61. Wilson AS, Power BE, Molloy PL. DNA hypomethylation and human diseases. Biochim Biophys Acta. 2007;1775:138-62.

62. Guo Z, Maki M, Ding R, Yang Y, Zhang B, Xiong L. Genome-wide survey of tissue-specific microRNA and transcription factor regulatory networks in 12 tissues. Sci Rep. 2014;4:5150.

63. Esteller M. Cancer epigenomics: DNA methylomes and histone-modification maps. Nat Rev Genet. 2007;8:286-98.

64. Baylin SB, Jones PA. A decade of exploring the cancer epigenome - biological and translational implications. Nat Rev Cancer. 2011;11:726-34.

65. Siddiqi S, Matushansky I. Piwis and piwi-interacting RNAs in the epigenetics of cancer. J Cell Biochem. 2012;113:373-80.

66. Martinez VD, Vucic EA, Thu KL, Hubaux R, Enfield KS, Pikor LA, et al. Unique somatic and malignant expression patterns implicate PIWIinteracting RNAs in cancer-type specific biology. Sci Rep. 2015;5:10423.

67. Lee JH, Engel W, Nayernia K. Stem cell protein Piwil2 modulates expression of murine spermatogonial stem cell expressed genes. Mol Reprod Dev. 2006;73:173-9.

68. Sasaki T, Shiohama A, Minoshima S, Shimizu N. Identification of eight members of the Argonaute family in the human genome. Genomics. 2003;82:323-30.

69. Unhavaithaya Y, Hao Y, Beyret E, Yin H, Kuramochi-Miyagawa S, Nakano T, et al. MILI, a PIWI-interacting RNA-binding protein, is required for germ line stem cell self-renewal and appears to positively regulate translation. J Biol Chem. 2009;284:6507-19.

70. Carmell MA, Xuan Z, Zhang MQ, Hannon GJ. The Argonaute family: tentacles that reach into RNAi, developmental control, stem cell maintenance, and tumorigenesis. Genes Dev. 2002;16:2733-42.

71. Chu H, Hui G, Yuan L, Shi D, Wang Y, Du M, et al. Identification of novel piRNAs in bladder cancer. Cancer Lett. 2015;356:561-7.

72. Yan H, Wu QL, Sun CY, Ai LS, Deng J, Zhang L, et al. piRNA-823 contributes to tumorigenesis by regulating de novo DNA methylation and angiogenesis in multiple myeloma. Leukemia. 2015;29:196-206.

73. Jacobs DI, Qin Q, Lerro MC, Fu A, Dubrow R, Claus EB, et al. PIWI-Interacting RNAs in gliomagenesis: evidence from post-GWAS and functional analyses. Cancer Epidemiol Biomarkers Prev. 2016;25:1073-80.

74. Liang D, Yang Y, Liu Y. The role Hiwi gene in the maintenance of lung cancer stem cell populations. Neoplasma. 2013.

75. Liu X, Sun Y, Guo J, Ma H, Li J, Dong B, et al. Expression of hiwi gene in human gastric cancer was associated with proliferation of cancer cells. Int J Cancer. 2006;118:1922-9.

76. Qiao D, Zeeman AM, Deng W, Looijenga LH, Lin H. Molecular characterization of hiwi, a human member of the piwi gene family whose overexpression is correlated to seminomas. Oncogene. 2002;21:3988-99. 
77. Siddiqi S, Terry M, Matushansky I. Hiwi mediated tumorigenesis is associated with DNA hypermethylation. PLoS ONE. 2012;7:e33711.

78. Taubert H, Greither T, Kaushal D, Wurl P, Bache M, Bartel F, et al. Expression of the stem cell self-renewal gene Hiwi and risk of tumour-related death in patients with soft-tissue sarcoma. Oncogene. 2007;26:1098-100.

79. Wang DW, Wang ZH, Wang LL, Song Y, Zhang GZ. Overexpression of hiwi promotes growth of human breast cancer cells. Asian Pac J Cancer Prev. 2014:15:7553-8.

80. Wang $X$, Tong $X$, Gao H, Yan X, Xu X, Sun S, et al. Silencing HIWI suppresses the growth, invasion and migration of glioma cells. Int J Oncol. 2014:45:2385-92.

81. Xie $Y$, Yang $Y$, Ji D, Zhang $D$, Yao $X$, Zhang $X$. Hiwi downregulation, mediated by shRNA, reduces the proliferation and migration of human hepatocellular carcinoma cells. Mol Med Rep. 2015;11:1455-61.

82. Lee JH, Schutte D, Wulf G, Fuzesi L, Radzun HJ, Schweyer S, et al. Stem-cell protein Piwil2 is widely expressed in tumors and inhibits apoptosis through activation of Stat3/Bcl-XL pathway. Hum Mol Genet. 2006;15:201-11.

83. Lu Y, Zhang K, Li C, Yao Y, Tao D, Liu Y, et al. Piwil2 suppresses p53 by inducing phosphorylation of signal transducer and activator of transcription 3 in tumor cells. PLoS ONE. 2012;7:e30999.

84. Su C, Ren ZJ, Wang F, Liu M, Li X, Tang H. PIWIL4 regulates cervical cancer cell line growth and is involved in down-regulating the expression of p14ARF and p53. FEBS Lett. 2012;586:1356-62.

85. Sugimoto K, Kage H, Aki N, Sano A, Kitagawa H, Nagase T, et al. The induction of H3K9 methylation by PIWIL4 at the p16Ink4a locus. Biochem Biophys Res Commun. 2007;359:497-502.

86. Huang G, Hu H, Xue X, Shen S, Gao E, Guo G, et al. Altered expression of piRNAs and their relation with clinicopathologic features of breast cancer. Clin Transl Oncol. 2013:15:563-8.

87. Zhang H, Ren Y, Xu H, Pang D, Duan C, Liu C. The expression of stem cell protein Piwil2 and piR-932 in breast cancer. Surg Oncol. 2013;22:217-23.

88. Fu A, Jacobs DI, Hoffman AE, Zheng T, Zhu Y. PIWI-interacting RNA 021285 is involved in breast tumorigenesis possibly by remodeling the cancer epigenome. Carcinogenesis. 2015;36:1094-102.

89. Cheng J, Deng H, Xiao B, Zhou H, Zhou F, Shen Z, et al. piR-823, a novel non-coding small RNA, demonstrates in vitro and in vivo tumor suppressive activity in human gastric cancer cells. Cancer Lett. 2012;315:12-7.

90. Cui L, Lou Y, Zhang X, Zhou H, Deng H, Song H, et al. Detection of circulating tumor cells in peripheral blood from patients with gastric cancer using piRNAs as markers. Clin Biochem. 2011;44:1050-7.

91. Li Y, Wu X, Gao H, Jin JM, Li AX, Kim YS, et al. Piwi-Interacting RNAs (piRNAs) are dysregulated in renal cell carcinoma and associated with tumor metastasis and cancer-specific survival. Mol Med. 2015;21:381-8.

92. Law PT, Qin H, Ching AK, Lai KP, Co NN, He M, et al. Deep sequencing of small RNA transcriptome reveals novel non-coding RNAs in hepatocellular carcinoma. J Hepatol. 2013;58:1165-73.

93. Lim SL, Ricciardelli C, Oehler MK, Tan IM, Russell D, Grutzner F. Overexpression of piRNA pathway genes in epithelial ovarian cancer. PLoS ONE. 2014;9:e99687.

94. Li D, Sun X, Yan D, Huang J, Luo Q, Tang H, et al. Piwil2 modulates the proliferation and metastasis of colon cancer via regulation of matrix metallopeptidase 9 transcriptional activity. Exp Biol Med (Maywood). 2012;237:1231-40.

95. El Bairi K, Tariq K, Himri I, Jaafari A, Smaili W, Kandhro AH, et al. Decoding colorectal cancer epigenomics. Cancer Genet. 2018;220:49-76.

96. Lao W, Grady WM. Epigenetics and colorectal cancer. Nat Rev Gastroenterol Hepatol. 2011;8:686-700.

97. Migliore L, Migheli F, Spisni R, Coppede F. Genetics, cytogenetics, and epigenetics of colorectal cancer. J Biomed Biotechnol. 2011;2011:792362

98. Pellegrini ML, Argibay P. Gomez DE [Genetics and epigenetics of colorectal cancer]. Acta Gastroenterol Latinoam. 2011:41:247-61.

99. Porcellini E, Laprovitera N, Riefolo M, Ravaioli M, Garajova I, Ferracin M. Epigenetic and epitranscriptomic changes in colorectal cancer: Diagnostic, prognostic, and treatment implications. Cancer Lett. 2018;419:84-95.
100. Huang J, Peng J, Guo L. Non-coding RNA: a new tool for the diagnosis, prognosis, and therapy of small cell lung cancer. JThorac Oncol. 2015:10:28-37.

101. Kaikkonen MU, Lam MT, Glass CK. Non-coding RNAs as regulators of gene expression and epigenetics. Cardiovasc Res. 2011;90:430-40.

102. Li M, Izpisua Belmonte JC. Roles for noncoding RNAs in cell-fate determination and regeneration. Nat Struct Mol Biol. 2015;22:2-4.

103. Piccoli MT, Gupta SK, Thum T. Noncoding RNAs as regulators of cardiomyocyte proliferation and death. J Mol Cell Cardiol. 2015;89:59-67.

104. Zhong F, Zhou N, Wu K, Guo Y, Tan W, Zhang H, et al. A SnoRNA-derived piRNA interacts with human interleukin-4 pre-mRNA and induces its decay in nuclear exosomes. Nucleic Acids Res. 2015;43:10474-91.

105. Watanabe T, Lin H. Posttranscriptional regulation of gene expression by Piwi proteins and piRNAs. Mol Cell. 2014;56:18-27.

106. Ishizu H, Siomi H, Siomi MC. Biology of PIWI-interacting RNAs: new insights into biogenesis and function inside and outside of germlines. Genes Dev. 2012;26:2361-73.

107. Zhang P, Kang JY, Gou LT, Wang J, Xue Y, Skogerboe G, et al. MIVI and piRNA-mediated cleavage of messenger RNAs in mouse testes. Cell Res. 2015:25:193-207.

108. Yin J, Jiang XY, Qi W, Ji CG, Xie XL, Zhang DX, et al. piR-823 contributes to colorectal tumorigenesis by enhancing the transcriptional activity of HSF1. Cancer Sci. 2017;108:1746-56.

109. Al Zaid Siddiquee K, Turkson J. STAT3 as a target for inducing apoptosis in solid and hematological tumors. Cell Res. 2008.18:254-67.

110. Yu H, Pardoll D, Jove R. STATs in cancer inflammation and immunity: a leading role for STAT3. Nat Rev Cancer. 2009:9:798-809.

111. Mai D, Ding P, Tan L, Zhang J, Pan Z, Bai R, et al. PIWl-interacting RNA54265 is oncogenic and a potential therapeutic target in colorectal adenocarcinoma. Theranostics. 2018;8:5213-30.

112. Mai $D$, Zheng Y, Guo H, Ding P, Bai R, Li M, et al. Serum piRNA-54265 is a new biomarker for early detection and clinical surveillance of human colorectal cancer. Theranostics. 2020;10:8468-78.

113. Weng W, Liu N, Toiyama Y, Kusunoki M, Nagasaka T, Fujiwara T, et al. Novel evidence for a PIWI-interacting RNA (piRNA) as an oncogenic mediator of disease progression, and a potential prognostic biomarker in colorectal cancer. Mol Cancer. 2018;17:16.

114. Cen H, Zheng S, Fang YM, Tang XP, Dong Q. Induction of HSF1 expression is associated with sporadic colorectal cancer. World J Gastroenterol. 2004:10:3122-6.

115. Lianos GD, Alexiou GA, Mangano A, Mangano A, Rausei S, Boni L, et al. The role of heat shock proteins in cancer. Cancer Lett. 2015:360:114-8.

116. Beere HM. "The stress of dying": the role of heat shock proteins in the regulation of apoptosis. J Cell Sci. 2004;117:2641-51.

117. Calderwood SK, Khaleque MA, Sawyer DB, Ciocca DR. Heat shock proteins in cancer: chaperones of tumorigenesis. Trends Biochem Sci. 2006;31:164-72.

118. Murphy ME. The HSP70 family and cancer. Carcinogenesis. 2013:34:1181-8.

119. Sabbah NA, Abdalla WM, Mawla WA, AbdAIMonem N, Gharib AF, Abdul-Saboor A, et al. piRNA-823 Is a Unique Potential Diagnostic NonInvasive Biomarker in Colorectal Cancer Patients. Genes. 2021;12.

120. Iyer DN, Wan TM, Man JH, Sin RW, Li X, Lo OS, et al. Small RNA Profiling of piRNAs in Colorectal Cancer Identifies Consistent Overexpression of piR-24000 That Correlates Clinically with an Aggressive Disease Phenotype. Cancers. 2020;12.

121. Koduru SV, Tiwari AK, Hazard SW, Mahajan M, Ravnic DJ. Exploration of small RNA-seq data for small non-coding RNAs in human colorectal cancer. J Genomics. 2017;5:16-31.

122. Vychytilova-Faltejskova P, Stitkovcova K, Radova L, Sachlova M, Kosarova Z, Slaba K, et al. Circulating PIWI-interacting RNAs piR-5937 and piR28876 are promising diagnostic biomarkers of colon cancer. Cancer Epidemiol Biomarkers Prev. 2018;27:1019-28.

123. Wang Z, Yang $H, M a D, M u Y$, Tan $X$, Hao Q, et al. Serum PIWl-interacting RNAs piR-020619 and piR-020450 are promising novel biomarkers for early detection of colorectal cancer. Cancer Epidemiol Biomarkers Prev. 2020;29:990-8

124. Sharma AK, Nelson MC, Brandt JE, Wessman M, Mahmud N, Weller $\mathrm{KP}$, et al. Human CD34(+) stem cells express the hiwi gene, a human homologue of the Drosophila gene piwi. Blood. 2001;97:426-34. 
125. Yang L, Bi L, Liu Q, Zhao M, Cao B, Li D, et al. Hiwi promotes the proliferation of colorectal cancer cells via upregulating global dna methylation. Dis Markers. 2015;2015:383056.

126. Zeng Y, Qu LK, Meng L, Liu CY, Dong B, Xing XF, et al. HIWl expression profile in cancer cells and its prognostic value for patients with colorectal cancer. Chin Med J (Engl). 2011;124:2144-9.

127. Oh SJ, Kim SM, Kim YO, Chang HK. Clinicopathologic implications of PIWIL2 expression in colorectal cancer. Korean J Pathol. 2012;46:318-23.

128. Li L, Yu C, Gao H, Li Y. Argonaute proteins: potential biomarkers for human colon cancer. BMC Cancer. 2010;10:38.

129. Klimenko OV, Shtilman M. Reprogramming of CaCo2 colorectal cancer cells after using the complex of poly-(N-vinylpyrrolidone) with small non-coding RNAs. Toxicol Rep. 2019;6:186-92.
130. Tosar JP, García-Silva MR, Cayota A. Circulating SNORD57 rather than piR-54265 is a promising biomarker for colorectal cancer: common pitfalls in the study of somatic piRNAs in cancer. RNA (New York, NY). 2021;27:403-10

\section{Publisher's Note}

Springer Nature remains neutral with regard to jurisdictional claims in published maps and institutional affiliations.
Ready to submit your research? Choose BMC and benefit from:

- fast, convenient online submission

- thorough peer review by experienced researchers in your field

- rapid publication on acceptance

- support for research data, including large and complex data types

- gold Open Access which fosters wider collaboration and increased citations

- maximum visibility for your research: over $100 \mathrm{M}$ website views per year

At BMC, research is always in progress.

Learn more biomedcentral.com/submissions 